\title{
Hydroxyapatite ceramics coating on magnesium alloy via a double layered capsule hydrothermal hot-pressing
}

\author{
Takamasa ONOKI ${ }^{\dagger}$ and Shin-ya YAMAMOTO \\ Department of Materials Science, Graduate School of Engineering, Osaka Prefecture University, \\ 1-1 Gakuen-cho, Nakaku, Sakai, Osaka 599-8531
}

\begin{abstract}
Hydroxyapatite (HA: $\mathrm{Ca}_{10}\left(\mathrm{PO}_{4}\right)_{6}(\mathrm{OH})_{2}$ ) ceramic coating on magnesium (Mg) alloy (AZ31; Mg-3Al-1Zn) was achieved simultaneously by using a double layered capsule hydrothermal hot-pressing (DC-HHP) method at the low temperature as low as $150^{\circ} \mathrm{C}$ with no special surface treatment on the surface of the $\mathrm{Mg}$ alloy. A mixture of calcium hydrogen phosphate dehydrate (DCPD) and calcium hydroxide $\left(\mathrm{Ca}(\mathrm{OH})_{2}\right)$ was used as a starting powder material for solidifying $\mathrm{HA}$. Pull-out tests were conducted in order to obtain an estimate of adhesive properties for the HA coating to the Mg alloy. Average value of maximum shear stress was determined to 6.1 $\pm 1.0 \mathrm{MPa}$. After the pull-out fracture tests, it was revealed that HA ceramics remained on the surface of the Mg alloy. The Mg alloy could be bonded to HA ceramics with good adhesive properties.
\end{abstract}

(๑2010 The Ceramic Society of Japan. All rights reserved.

Key-words : Low temperature, Composite, Biomaterials

[Received February 9, 2010; Accepted June 17, 2010]

\section{Introduction}

Magnesium ( $\mathrm{Mg}$ ) and its alloys have been limited thus far due to their very low corrosion resistance. Therefore, various types of coating on $\mathrm{Mg}$ alloys have been developed and some of them are practically used. ${ }^{1), 2)}$ Conventional anticorrosion coatings for $\mathrm{Mg}$ alloys contain chromates and manganates that are harmful. 3$), 4)$ Therefore, the development of coatings on $\mathrm{Mg}$ materials is of great interest.

For biomedical usage, $\mathrm{Mg}$ alloys are possible candidates for use in cardiovascular intervention and osteosynthesis. ${ }^{5)-10)} \mathrm{Mg}$ alloys have appropriate corrosion rates in physiological media. Progress in $\mathrm{Mg}$ alloy development, resulting mainly in new compositions and high purity alloys, has produced an increased corrosion resistance and thus a reduced hydrogen-evolution rate. ${ }^{11), 12)}$ The hydrogen evolution in filigree implants, such as cardiovascular stents, seems to be of minor importance; preclinical and clinical studies indicate good biocompatibility, with minimal inflammatory changes and complete absorption within two months. ${ }^{7), 8), 13), 14)}$ Moreover, Mg materials also show a Young's modulus similar to that of bone (Young's modulus: $E=3-20 \mathrm{GPa}$ ), which makes it particularly interesting for osteosynthesis applications. As early as the 1930s, feasibility studies showed the good resorbability and high biocompatibility of $\mathrm{Mg}$ alloy implants in bone. ${ }^{15)}$ In osteosynthesis applications, however, hydrogen evolution remains problematic through the chemical reaction as follows:

$$
\mathrm{Mg}+2 \mathrm{H}_{2} \mathrm{O} \rightarrow \mathrm{Mg}^{2+}+2 \mathrm{OH}^{-}+\mathrm{H}_{2} \text {. }
$$

Recently, a few research of hydroxyapatite (HA) coating on $\mathrm{Mg}$ alloys have been conducted. ${ }^{16), 17)}$ It is well known that HA ceramics can directly bond to living bone when used as bone replacement materials. Hydroxyapatite (HA) is expected to show

\footnotetext{
Corresponding author: T. Onoki; E-mail: onoki@mtr.osakafu-u. ac.jp
}

high corrosion resistance because the thermodynamic stability of the HA structure is remarkably high, ${ }^{18)}$ as well as no environmental toxicity since HA is an inorganic component of human bone. However, few attempts have been made so far to apply HA as a biocompatible coating for structural $\mathrm{Mg}$ alloys. This is because corrosion of the $\mathrm{Mg}$ alloy substrate in aqueous solutions is inevitable due to the high ionization tendency of $\mathrm{Mg},{ }^{19)}$ and the released $\mathrm{Mg}$ ions prevents HA crystallization with the substitution of $\mathrm{Mg}$ atom for the $\mathrm{Ca}$ atom in the HA structure. ${ }^{20), 21)}$ The HA structure is destabilized by a decrease in the atomic ratio of $\mathrm{Ca}$ to $\mathrm{P}(\mathrm{Ca} / \mathrm{P}$ ratio) in the structure with increase of $\mathrm{Mg}$ ion concentration in the synthesis system. ${ }^{20)}$ Direct synthesis of HA on substrates of $\mathrm{Mg}$ and its alloys in aqueous solutions has been a scientific challenge because $\mathrm{Mg}$ ions prevent HAp crystallization. If direct synthesis of HA on $\mathrm{Mg}$ alloys and direct bonding HA and substrate of $\mathrm{Mg}$ alloys can be achieved, $\mathrm{Mg}$ alloys has a great potentials as newly developed biomedical materials.

In our previous studies, ${ }^{22)-25)}$ it has been demonstrated that bonding HA ceramics and pure titanium (Ti) substrate can be achieved by employing the hydrothermal hot-pressing (HHP) method. ${ }^{22)}$ Additionally, HA ceramic coatings on Ti substrates were obtained with no chemical decomposition and strong adhesive properties by using DC-HHP techniques. ${ }^{24)}$ It is easily forecasted that low temperature techniques is required for HA coating on $\mathrm{Mg}$ alloys, because $\mathrm{Mg}$ has higher chemical activity. So, we have been investigated possibility of direct bonding HA ceramics and substrate of $\mathrm{Mg}$ alloy by using the HHP techniques. DC-HHP techniques have been developed in order to prepare HA coating layers on a cylindrical rod with the objective of applying the hydrothermal hot-pressing method to substrates with more complicated configurations, as shown in Fig. 1. ${ }^{24)}$ This paper demonstrates that direct bonding HA ceramics and Mg alloy can be achieved, and that HA ceramic coating to Mg alloys can be achieved by using the DC-HHP method. And it is shown that $\mathrm{Mg}$ materials have potentials as newly developed biomedical materials. 


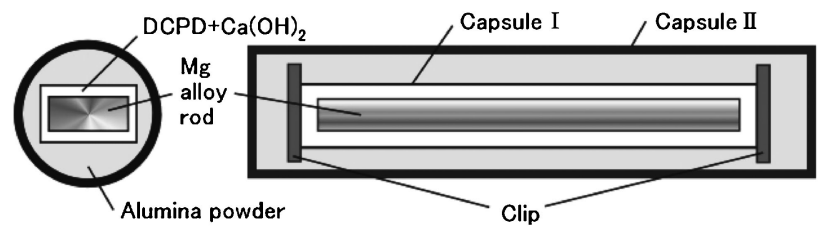

(a)

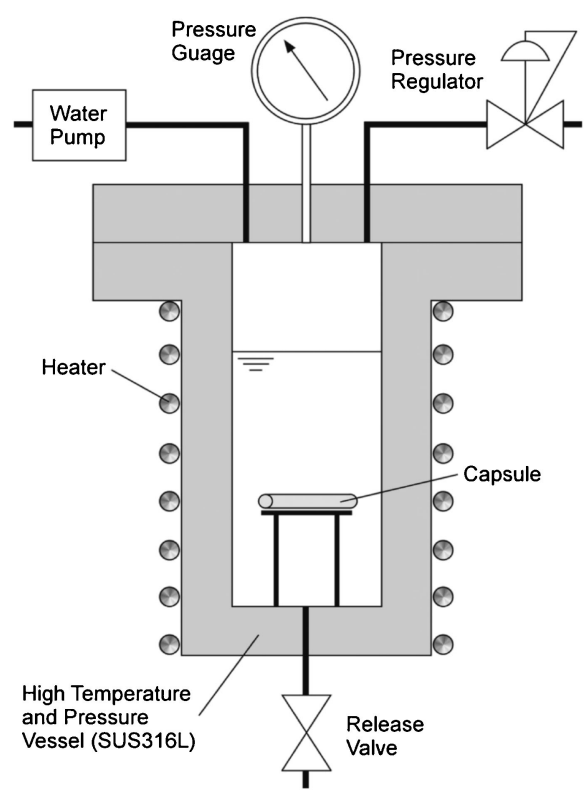

(b)

Fig. 1. Schematic illustration of the double layered capsule hydrothermal hot-pressing (DC-HHP) method in a cross section view; (a) capsule and (b) autoclave.

\section{Experimental}

\subsection{Starting materials}

A commercially available $\mathrm{Mg}$ alloy (AZ31; Mg-3Al-1Zn, OSAKA FUJI CORPORATION, Japan) was used in this experiment as a typically conventional substrate of $\mathrm{Mg}$ alloy. The Mg alloy was cut into a size of $1.5 \mathrm{~mm}$ thickness, $2.0 \mathrm{~mm}$ width and $20 \mathrm{~mm}$ length, respectively. The rods of $\mathrm{Mg}$ alloy were cleaned in ethanol by using an ultrasonic cleaner. The surfaces of the rods were finished using 2000\# emery paper in ethanol lubricant. After the surface finish with emery paper, the $\mathrm{Mg}$ alloy rods were washed again, and then dried in air.

DCPD used as a starting powder was prepared by mixing $1.0 \mathrm{~mol} / \mathrm{dm}^{3}(M)$ calcium nitrate solution $\left(99.0 \% ; \mathrm{Ca}\left(\mathrm{NO}_{3}\right)_{2}\right.$. $4 \mathrm{H}_{2} \mathrm{O}$, KANTO CHEMICAL, Japan) and $1.0 \mathrm{M}$ diammonium hydrogen phosphate solution $\left(98.5 \%\right.$; $\left(\mathrm{NH}_{4}\right)_{2} \mathrm{HPO}_{4} ; \mathrm{KANTO}$ CHEMICAL, Japan). The mixing was carried out at a room temperature (approximately $20^{\circ} \mathrm{C}$ ). In order to control the value of $\mathrm{pH}$, acetic acid and ammonia solution were added. The precipitate from the mixture was filtered and washed with deionized water and acetone. The washed filter cake was ovendried at $50^{\circ} \mathrm{C}$ for $24 \mathrm{~h}$, and then the dried cake was ground to a powder. The synthesyed DCPD and calcium hydroxide $(95.0 \%$; $\mathrm{Ca}(\mathrm{OH})_{2}$; KANTO CHEMICAL, Japan) were mixed in a mortar for 90 min with a $\mathrm{Ca} / \mathrm{P}$ ratio of 1.67 . The synthesis and solidification of HA through the chemical reaction as follows:

$$
\begin{aligned}
& 6 \mathrm{CaHPO}_{4} \cdot 2 \mathrm{H}_{2} \mathrm{O}+4 \mathrm{Ca}(\mathrm{OH})_{2} \\
& \quad \rightarrow \mathrm{Ca}_{10}\left(\mathrm{PO}_{4}\right)_{6}(\mathrm{OH})_{2}+18 \mathrm{H}_{2} \mathrm{O} .
\end{aligned}
$$

\subsection{Double layered capsule hydrothermal hot- pressing (DC-HHP) method}

DC-HHP method uses a capsule having the double layered structure, which is subjected to isostatic pressing under hydrothermal conditions. A schematic illustration of the capsule in a cross section view is shown in Fig. 1(a). Firstly, the $\mathrm{Mg}$ alloy rod and the powder mixture of DCPD and $\mathrm{Ca}(\mathrm{OH})_{2}$ were placed into a polyethylene $(\mathrm{PE})$ tube. The weight of the $\mathrm{DCPD}$ and $\mathrm{Ca}(\mathrm{OH})_{2}$ powder mixture put into was approximate $0.1 \mathrm{~g}$. The powder mixture was loaded into the PE tube such that the $\mathrm{Mg}$ alloy rod was concentrically positioned with respect to the tube axis. Both the ends of the PE tube were fastened with paper staples. The sample assemblage encapsulated using the PE tube is called "capsule I" in this study. Secondly, the capsule I was further encapsulated using a poly-vinylidene-chloride (PVC; $11 \mu \mathrm{m}$ thickness, Asahi-KASEI, Japan) film. Between the capsule I and PVC film, alumina powder $(3.0 \mu \mathrm{m}$ diameter; Buehler Ltd., USA) was placed. The thickness of the alumina powder layer was approximately $5 \mathrm{~mm}$. The capsule prepared using the PVC film is called "capsule II". Then, the PVC film was sealed off. The capsules prepared were put into a batch type high temperature and pressure vessel (volume: $300 \mathrm{ml}$, SUS316L, AKICO, Japan) for hydrothermal treatment. A schematic illustration of the autoclave for the hydrothermal treatment is shown in Fig. 1(b). The deionized water in the vessel serves as a medium for isostatic pressing. The vessel was heated up to $150^{\circ} \mathrm{C}$, and then the temperature was kept constant for $3 \mathrm{~h}$. The pressure was kept at $40 \mathrm{MPa}$ using pressure regulator. After the treatment, the vessel was naturally cooled down to a room temperature, and the capsules removed from the vessel. The HA ceramic coated samples were obtained.

\subsection{Adhesion properties evaluation}

Pull-out tests were conducted in order to evaluate the adhesion strength of the ceramic coating and the Mg alloy substrate. ${ }^{24)} \mathrm{A}$ schematic illustration of the pull-out testing method was drawn in Fig. 2. The samples were embedded into an epoxy resin placed in a sample attachment. And then the protruding part of the coating was removed with a grinder. The removed coating material was applied to power X-ray diffraction analysis (XRD) in order to identify the crystals in the treated specimens. The specimens were loaded with an Instron-type testing machine at a cross-head speed of $1.0 \mathrm{~mm} / \mathrm{min}$ until the $\mathrm{Mg}$ alloy rods were pulled out

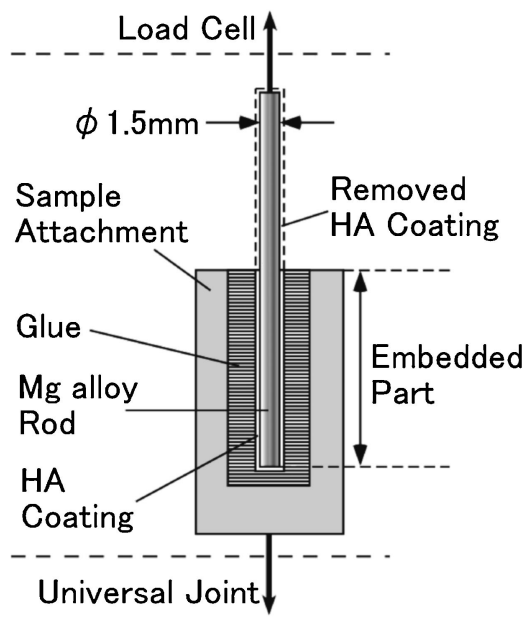

Fig. 2. Schematic illustration of the pull-out testing method in a cross section view. 


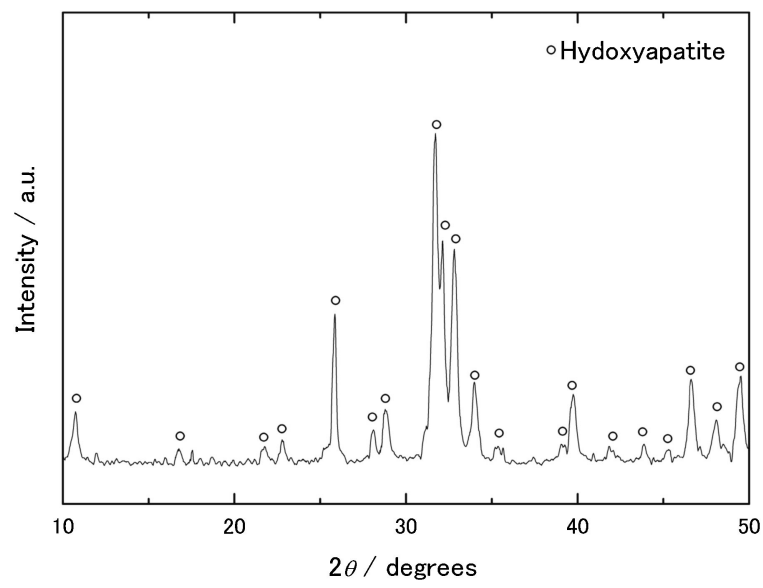

Fig. 3. X-ray diffraction pattern of the HA coating.

entirely. The sample attachment was connected to a universal joint. The upper part of the $\mathrm{Mg}$ rod was gripped with a manual wedge grip and then loaded with the testing machine through a load-cell. In order to evaluate the adhesion properties of the HA coating on the $\mathrm{Mg}$ rod quantitatively, the shear strength was calculated from the results of the pull-out testing. Maximum shear strength $\tau_{\max }$ is computed using the following equation:

$$
\tau_{\max }=\frac{P_{\max }}{S}
$$

where $\boldsymbol{S}$ is the embedded superficial area of the $\mathrm{Mg} \operatorname{rod}$ and $\boldsymbol{P}_{\max }$ is the maximum load in the pull-out test.

\section{Results and discussion}

XRD analysis showed that the DCPD and $\mathrm{Ca}(\mathrm{OH})_{2}$ powder materials were completely transformed into HA by the HHP treatment, as given in Fig. 3. There is no effect of the Mg alloy substrate on transforming behavior from the starting powder to HA. Furthermore, the XRD analysis shows that the low temperature hydrothermal method induced no chemical decomposition of hydroxyapatite and $\mathrm{Mg}$ alloy unlike high temperature methods such as a plasma splaying method.

A load-displacement curves obtained from the pull-out tests was shown for the HA coated $\mathrm{Mg}$ alloy substrates in Fig. 4, in comparison with HA coated pure Ti. From the load-displacement curve drawn in Fig. 4(a), the maximum shear stress value; $\tau_{\max }$ of the $\mathrm{Mg}$ alloy specimen was computed approximate $7.1 \mathrm{MPa}$. Average value of $\tau_{\max }$ was calculated to $6.1 \pm 1.0 \mathrm{MPa}$ within 5 specimens of the HA coated Mg alloys. On the other hand, that of pure $\mathrm{Ti}$ was evaluated to $1.5 \pm 0.1 \mathrm{MPa}$. The $\mathrm{Mg}$ alloy has approximate 4 times higher value. Figure 5 shows the appearance of the specimen after the pull-out testing. The left part of the specimen was initially embedded in the epoxy resin. It can be seen from Fig. 5 that the coating material remained on the $\mathrm{Mg}$ surface after the pull-out testing. If the interface between the HA and $\mathrm{Mg}$ was held just by interfacial friction with no significant chemical bond, no HA ceramics would remain on the Mg alloy surfaces after the pull-out testing. On the other hand, there was no HA ceramics on the Ti surface, like as shown in Fig. 5. The remaining HA ceramics demonstrates that Mg materials have possibility for directly bonding to HA ceramics through the HHP techniques. These superior adhesive properties of the $\mathrm{Mg}$ material could be derived from high chemical activity of magnesium and its alloys, because magnesium is metal of the alkaline earth.
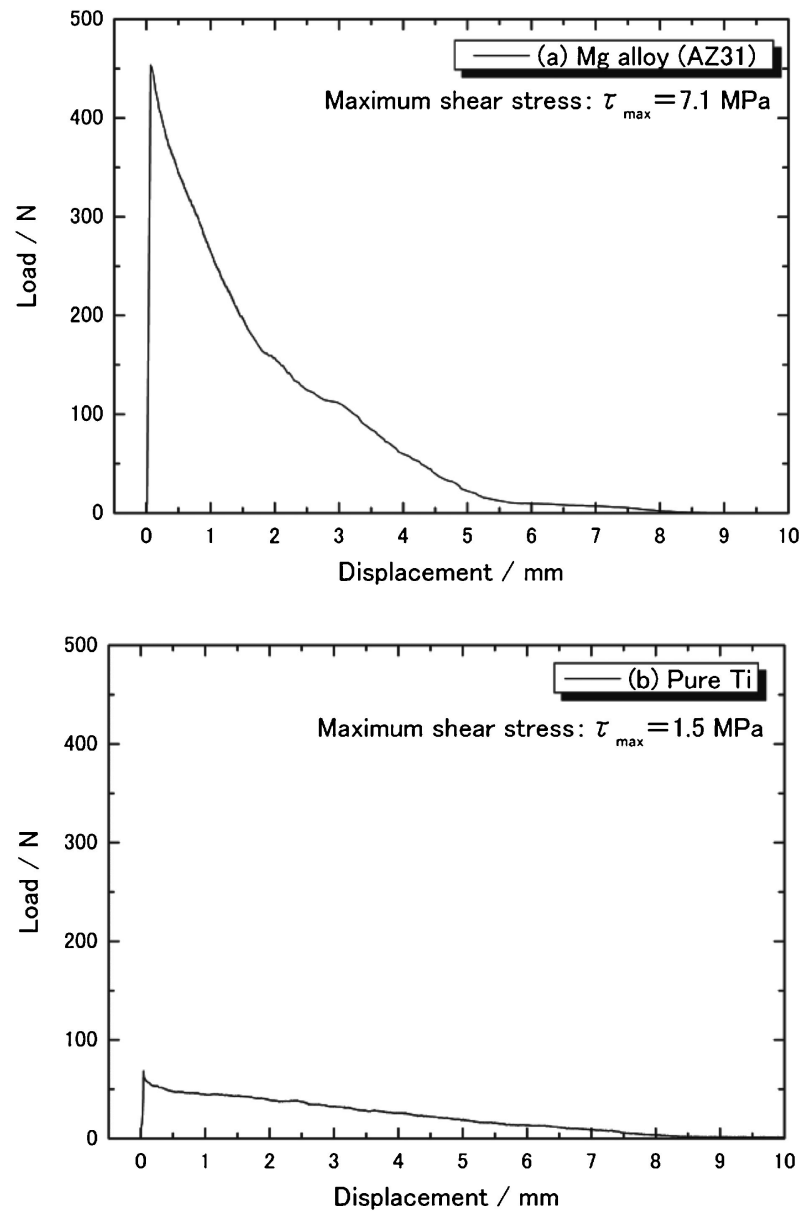

Fig. 4. Load-displacement curves of the pull-out testing for the HA coated specimens (a) Mg alloy (AZ31) and (b) commercially available pure Ti.

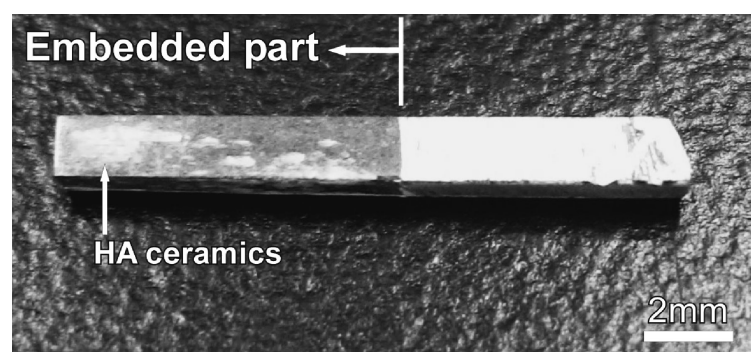

Fig. 5. Photograph of the HA coated Mg alloy specimen after the pullout testing.

It was known that improving $\mathrm{HA}$ adhesive properties to $\mathrm{Ti}$ substrate surface could be achieved by surface treatments on Ti substrate. ${ }^{25)}$ Therefore $\mathrm{Mg}$ materials have a potential for improving of HA adhesive properties through surface treatments. And it is needed to be investigated optimal interfacial architecture between the HA ceramics and the Mg. The above shown results demonstrate that possibility of newly developed biomaterials which is composed of Mg materials and HA ceramics, and that the usefulness of the DC-HHP method for HA ceramics coating to the $\mathrm{Mg}$ alloy (AZ31) and other $\mathrm{Mg}$ materials.

\section{Summary}

In this paper, it was shown that hydroxyapatite (HA) ceramic coating to magnesium alloy (AZ31) could achieved through the 
double layered capsule hydrothermal hot-pressing (DC-HHP) method at the temperature as low as $150^{\circ} \mathrm{C}$ with no special surface treatment on the $\mathrm{Mg}$. The pull-out tests conducted to the HA coating Mg alloy rod in order to evaluate adhesive properties of the HA coatings. Average value of maximum shear stress was determined to $6.1 \pm 1.0 \mathrm{MPa}$. It was revealed that HA ceramics remained on the $\mathrm{Mg}$ alloy surface after the pull-out testing. These good adhesive properties could be derived from highly chemical activity of magnesium element. Magnesium materials have potentials as newly developed biomedical materials.

Acknowledgements This work was partly supported by a "Grant-in-Aid for Young Scientists (B) 18760516 and 20760490" from the Ministry of Education, Culture, Sports, Science and Technology of Japan.

\section{References}

1) J. E. Gray and B. Luan, J. Alloys Compd., 336, 88-113 (2002).

2) C. Blawert, W. Dietzel, E. Ghali and G. Song, Adv. Eng. Mater., 8, 511-533 (2006).

3) P. Kurze, "Magnesium Technology, Metallurgy, Design Data, Applications," Ed. by H. E. Friedrich and B. L. Mordike, Springer-Verlag, Berlin (2006) Chap. 7.

4) "Handbook of Advanced Magnesium Technology," Ed. by the Japan Institute of Light Metals, Kallos Publishing, Tokyo (2000) Chaps. 1, 8 and 11.

5) F. Witte, J. Fischer, J. Nellesen, H. Crostack, V. Kaese, A. Pisch, F. Beckmann and H. Windhagen, Biomaterials, 27, 1013-1018 (2006).

6) M. P. Staiger, A. M. Pietak, J. Huadmai and G. Dias, Biomaterials, 27, 1728-1734 (2006)

7) B. Heublein, R. Rohde, V. Kaese, M. Niemeyer, W. Hartung and A. Haverich, Heart, 89, 651-656 (2003).

8) R. Erbel, C. Di Mario, J. Bartunek, J. Bonnier, B. de Bruyne, F. R. Eberli, P. Erne, M. Haude, B. Heublein, M. Horrigan, C. Ilsley, D. Böse, J. Koolen, T. F. Lüscher, N. Weissman and R. Waksman, Lancet, 369, 1869-1875 (2007).
9) H. Hermawan, H. Alamdari, D. Mantovani and D. Dubé, Powder Metall., 51, 38-45 (2008)

10) M. Peuster, C. Hesse, T. Schloo, C. Fink, P. Beerbaum and C. Von Schnakenburg, Biomaterials, 27, 4955-4962 (2006).

11) F. Witte, V. Kaese, H. Haferkamp, E. Switzer, A. MeyerLindenberg, C. J. Wirth and H. Windhagen, Biomaterials, 26, 3557-3563 (2005).

12) B. Zberg, P. J. Uggowitzer and J. F. Loffler, Nat. Mater, 8, 887-891 (2009).

13) P. Peeters, M. Bosiers, J. Verbist, K. Deloose and B. Heublein, J. Endovasc. Ther., 12, 1-5 (2005).

14) C. Di Mario, H. Griffiths, O. Goktekin, N. Peeters, J. Verbist, M. Bosiers, K. Deloose, B. Heublein, R. Rohde, V. Kasese, C. Ilsley and R. Erbel, J. Interv. Cardiol., 17, 391-395 (2004).

15) E. D. McBride, South. Med. J., 31, 508-515 (1938).

16) Y. W. Song, D. Y. Shan and E. H. Han, Mater. Lett., 62, 32763279 (2008).

17) S. Hiromoto and A. Yamamoto, Electrochim. Acta, 54, 70857093 (2009).

18) D. MacConnell, "Apatite: Its Crystal Chemistry, Mineralogy, Utilization, and Geologic and Biologic Occurrences," Springer-Verlag, New York (1973) Chap. 5.

19) M. Pourbaix, "Atlas of Electrochemical Equilibria in Aqueous Solutions," English ed., National Association of Corrosion Engineers, Texas (1974) Chap. 4.

20) A. Bigi, G. Falini, E. Foresti, A. Ripamonti, M. Gazzano and N. Roveri, J. Inorg. Biochem., 49, 69-78 (1993).

21) I. V. Fadeev, L. I. Shvorneva, S. M. Barinov and V. P. Orlovskii, Inorg. Mater., 39, 947-950 (2003).

22) T. Onoki, K. Hosoi and T. Hashida, Scr. Mater, 52, 767-770 (2005).

23) T. Onoki, X. Wang, S. Zhu, N. Sugiyama, Y. Hoshikawa, M. Akao, N. Matsushita, A. Nakahira, E. Yasuda, M. Yoshimura and A. Inoue, Mater. Sci. Eng., B, 161, 27-30 (2009).

24) T. Onoki and T. Hashida, Surf. Coat. Tech., 200, 6801-6807 (2006).

25) T. Onoki, K. Hosoi, T. Hashida, Y. Tanabe, T. Watanabe, E. Yasuda and M. Yoshimura, Mater. Sci. Eng., C, 28, 207-212 (2008). 